\title{
Parâmetros fisiológicos de ovinos Santa Inês submetidos a sombreamento com tela de polipropileno
}

\author{
Fabiano A. de Oliveira', Sílvia H. N. Turco ${ }^{2}$, Iran Borges ${ }^{3}$, \\ Carlos A. A. Clemente ${ }^{4}$, Thiago V. C. Nascimento ${ }^{1}$ \& João B. Loiola Filho ${ }^{1}$
}

\begin{abstract}
RESUMO
Neste trabalho objetivou-se verificar a influência do uso de tela de polipropileno com $80 \%$ de retenção luminosa nas respostas fisiológicas de ovinos da raça Santa Inês submetidos a pastejo; para isto, um experimento foi montado em Petrolina, PE, no período de junho a novembro de 2010 e adotados dois tratamentos (com sombreamento e sem sombreamento) com 20 animais em cada um. Aferiu-se a temperatura retal, a temperatura da superfície cutânea e a frequência respiratória, às $7 \mathrm{~h}$ e $15 \mathrm{~h}$, duas vezes por semana. Foram medidos dados meteorológicos visando à determinação do índice de temperatura de globo negro e umidade, a cada 2 h, por 24 h durante todo o experimento. Verificou-se, após análise dos dados, que os ovinos do tratamento com sombreamento sofreram redução em todas as variáveis fisiológicas avaliadas, quando comparados com os do tratamento sem sombreamento. A utilização do sombreamento é justificada, em especial no período da tarde visto que todas as variáveis sofrem maior alteração.
\end{abstract}

Palavras-chave: ambiência, fisiologia, radiação, temperatura retal, termorregulação

\section{Physiological parameters of Santa Inês sheep submitted to shaded environment by polypropylene mesh}

\begin{abstract}
In order to verify the influence of the use of polypropylene fabric with light retention 80 in physiological responses of Santa Inês sheep under grazing, an experiment was conducted in Petrolina, PE, between June to November of 2010. Two treatments (with and without shading) were adopted with 20 animals in each. Rectal temperature, skin surface temperature and respiratory rate at 7:00 am and 3:00 pm twice a week were measured. Meteorological data were recorded for the determinations of the temperature index of black globe and humidity, every 2:00 hours during 24 hours, throughout the experiment. It was verified after analysis of the data that sheep under shade treatment had suffered reductions in all physiological variables evaluated, when compared with the treatment without shade. The use of shading is justified, in particular in the afternoon, since all variables showed greater change.
\end{abstract}

Key words: ambience, physiology, radiation, rectal temperature, thermoregulation

CCA/UINVASF, Rodovia BR 407, Km 12 Lote 543 - Projeto Nilo Coelho - S/N C1. CEP 56300-000, Petrolina, PE. (74) 91155174. E-mail: agronomoca@gmail.com; thiagovcn_vet@hotmail.com; boscouaua@hotmail.com

2 CENAMB/UNIVASF, Av. Antônio Carlos Magalhães, 510 - Country Club. CEP 48902-300, Juazeiro, BA. (74) 21027621. E-mail: silvia.turco@univasf.edu.br

${ }^{3}$ EV/UFMG, Av. Antônio Carlos, 6627, Campus Pampulha, CEP 30123-970, Belo Horizonte, MG. Fone (31) 3409-2184, E-mail: iranborges@ufmg.br

${ }^{4}$ EV/UFMG. Fone (31) 3409-2249, E-mail: clemente.caa@gmail.com 


\section{INTRODUÇÃO}

O efetivo ovino nacional conta com 17.380.581 milhões de cabeças, sendo $57,2 \%$ deste rebanho (9.941.692 cabeças), explorados na região Nordeste, como registrou o IBGE (2006). Em Pernambuco a exploração tem apresentado crescimento acentuado, aumento que pode ser atribuído ao grande incremento no efetivo ou mesmo pelo aumento no número de propriedades, ao passo que ocorreu aumento da demanda por carne ovina.

Apesar da rusticidade, vista como característica da maioria das raças exploradas no Nordeste, os índices de produtividade não são muito satisfatórios pois as práticas de manejo alimentar e sanitárias adotadas não são as mais adequadas, o que contribui para uma baixa eficiência produtiva; pode-se, ainda, atribuir os baixos índices aos efeitos diretos e indiretos do ambiente tropical, que podem comprometer o bem-estar animal.

Cada espécie animal possui uma faixa de temperatura de conforto, zona termoneutra, definida como a faixa de temperatura em que a produção é ótima e o gasto de energia para termorregulação é mínimo. No caso da espécie ovina em especial, a zona de conforto térmico está na faixa de -2 a 20 ${ }^{\circ} \mathrm{C}$ (Cezar et al., 2004) dependendo da raça, do tamanho e da fase produtiva etc. Dentro da zona de conforto térmico apenas $20 \%$ das perdas de calor são feitos através da via respiratória; quando expostos a temperaturas acima de $35{ }^{\circ} \mathrm{C}$ a perda de calor por esta via chega a $60 \%$ do calor total perdido.

São crescentes os cruzamentos entre espécies que reúnem características que podem trazer vários benefícios para a sobrevivência em regiões tropicais, como no Nordeste brasileiro. Os ovinos da raça Dorper, por exemplo, são semilanados e vêm sendo utilizados no Nordeste do Brasil para cruzamentos com Santa Inês e SRD visando, desta maneira, buscar uma melhoria nos índices produtivos e na qualidade da carcaça.

Assim, as avaliações de adaptabilidade ao calor podem ser realizadas por meio de testes de adaptabilidade fisiológica e de adaptabilidade de rendimento ou produção. A temperatura retal e a frequência respiratória são as melhores variáveis fisiológicas para estimar esta tolerância. Santos et al. (2003) concluíram, estudando as respostas fisiológicas de ovinos Santa Inês, Morada Nova e de seus mestiços com a raça Dorper, que os animais da raça Morada Nova foram os mais adaptados enquanto os mestiços Santa Inês x Dorper se apresentaram como os menos adaptados.

Segundo Encarnação (1989) em regiões de altas temperaturas e radiação a prática de sombreamento reduz consideravelmente os efeitos da radiação tornando viável a exploração de espécies oriundas de regiões de climas mais amenos, razão por que se objetivou, nesta pesquisa, verificar os efeitos do sombreamento com tela de polipropileno com $80 \%$ de retenção luminosa sobre as respostas fisiológicas de ovinos Santa Inês sob pastejo em piquetes de capim tifton 85 .

\section{Material e Métodos}

O experimento foi conduzido no Campo Experimental de Bebedouro localizado na Embrapa Semiárido, em Petrolina,
PE, o qual realizado em duas épocas do ano: Época 1 - Junho a Agosto, período durante o qual se concentram as menores médias mensais $\left(23,8\right.$ a $\left.25,1{ }^{\circ} \mathrm{C}\right)$ e Época 2 - Setembro a Novembro, com as maiores médias mensais do ano (27,7 e 28,9 ${ }^{\circ} \mathrm{C}$ ) buscando submeter os animais sob influência das diferentes condições de ambiente climático no ano (Teixeira et al., 2004). Dentro de cada época experimental (60 dias), 15 dias foram destinados a um período de adaptação. Utilizou-se uma área $6.144 \mathrm{~m}^{2}$, dividida em 24 piquetes $(15 \times 16 \mathrm{~m})$ formados por gramínea (tifton 85) onde os animais permaneceram durante dois dias em cada piquete, formando um sistema de pastejo intermitente; aqui, os animais permaneceram todo o período experimental. Os animais foram submetidos a dois tratamentos cada um com 20 animais dispondo um de área sombreada dentro do piquete, proporcionado por tela de polipropileno preta com $80 \%$ de retenção luminosa, totalizando $50 \mathrm{~m}^{2}$, correspondendo à oferta de $2,5 \mathrm{~m}^{2}$ de sombra por animal, ou seja, $21 \%$ da área do piquete, disponível durante todo o dia, assim denominado - tratamento com sombreamento (TCS). Este sombreamento foi disponibilizado nos piquetes sendo uma opção dos animais em ficar na sombra ou exposto ao sol. No segundo tratamento os animais ficaram expostos à radiação direta nos piquetes, sendo denominado - Tratamento sem sombreamento (TSS) (Figura 1).

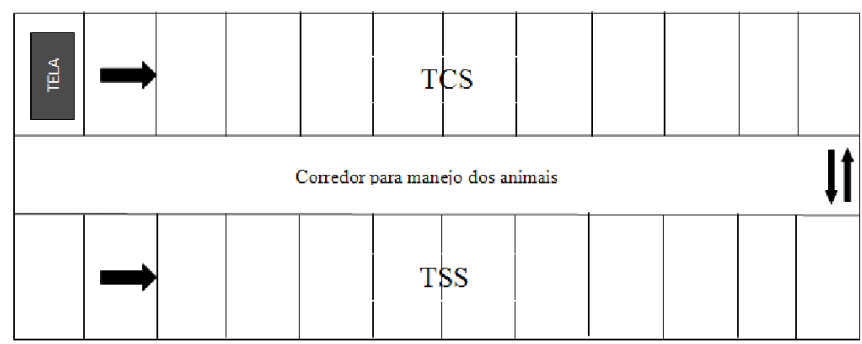

TCS - Tratamento com sombreamento

TSS - Tratamento sem sombreamento

Figura 1. Croqui da distribuição dos piquetes na área experimental

Utilizaram-se 20 fêmeas da raça Santa Inês selecionadas de acordo com a idade, que variou de 12 a 30 meses, peso, em média $16 \mathrm{~kg}$ e cor da pelagem, visto que ocorreram as mais diversas combinações. Foram submetidas à avaliação de escore corporal, por meio de avaliação subjetiva, sendo esta visual e tátil, visando estimar a quantidade de tecido muscular e adiposo depositados sobre o esqueleto do animal buscando, assim, a uniformidade do lote. Os animais foram identificados com brincos e/ou coleiras numeradas. Dentre as 20 ovelhas usadas por tratamento 10 foram selecionadas para as avaliações.

Os piquetes foram adubados e feito controle constante da irrigação. Utilizaram-se bebedouros e comedouros para o fornecimento de água e sal mineral. O experimento foi conduzido em sistema de pastejo intermitente em que os animais passaram por todos os piquetes recebendo condições iguais de ambiente e manejo, salvo a oferta de sombra fornecida a apenas um grupo.

Os dois tratamentos receberam o mesmo manejo nutricional alimentando-se exclusivamente da oferta de 
forragem disponível nos piquetes (Capim tifton 85) e com o fornecimento de suplementação mineral de acordo com as exigências. Foi realizado o acompanhamento periódico da saúde dos animais.

As variáveis fisiológicas das ovelhas (conforme descritas abaixo) foram efetuadas duas vezes a cada semana, de maneira que somente o grupo de animais destinados a essas avaliações (10 animais) foi acompanhado para tais aferições.

A frequência respiratória $\left(\mathrm{FR}, \mathrm{mov} \mathrm{min}^{-1}\right)$, temperatura retal $\left(\mathrm{TR},{ }^{\circ} \mathrm{C}\right)$ e temperatura da superfície cutânea $\left(\mathrm{TC},{ }^{\circ} \mathrm{C}\right)$ foram avaliadas no turno da manhã $(7 \mathrm{~h})$ e no turno da tarde $(15 \mathrm{~h})$, nos dias predeterminados. Por se tratar de manejo com animais a pasto, os mesmos foram conduzidos a um piquete menor para facilitar a coleta dos dados realizando-se, assim, o mínimo de movimentos bruscos que pudessem deixá-los estressados, alterando tais parâmetros.

A FR foi obtida observando-se por $15 \mathrm{~s}$ os movimentos respiratórios concentrando a visualização na região do flanco. Foram feitas três contagens em cada animal obtendo-se uma média, que foi multiplicada por quatro.

Para determinação da TR utilizou-se um termômetro clínico digital com precisão de $\pm 0,5{ }^{\circ} \mathrm{C}$. Para a aferição o termômetro foi introduzido no reto do animal a $10 \mathrm{~cm}$, permanecendo até a estabilização da temperatura.

A TC também foi avaliada utilizando-se um termômetro de infravermelho que foi posicionando a $5 \mathrm{~cm}$ da superfície cutânea, em quatro pontos distintos, sendo a cabeça, pescoço, flanco e jarrete calculada, posteriormente, a média desses valores.

Os dados climáticos foram obtidos através dos registros da estação climatológica de Petrolina, PE (latitude: 9 $9^{\circ}$, longitude: $40^{\circ} 22^{\prime}$ e altitude: $365,5 \mathrm{~m}$ ), situada na Embrapa Semiárido e em uma miniestação que foi montada na área sombreada para simular as condições às quais os animais estavam submetidos.

Em cada tratamento foi instalado um termômetro de globo negro, posicionado a uma altura equivalente à linha dorso lombar dos animais, junto aos quais foram instalados psicrômetros, todos conectados a um Data Logger, além de termo-anemômetros digitais portáteis.

A umidade do ar (UR, \%) foi obtida em tabelas meteorológicas a partir dos registros de temperatura de bulbo seco (Tbs) e temperatura de bulbo úmido (Tbu) e também após tabulação dos registros, no caso do TSS; no TCS, esses valores foram obtidos diretamente da miniestação.

$\mathrm{O}$ índice de temperatura de globo negro e umidade (ITGU), desenvolvido por Buffington (1977), foi adotado como o índice de conforto térmico para estimativa da situação de adaptação dos animais.

Assim:

$$
\mathrm{ITGU}=\mathrm{Tg}+0,36+41,5
$$

onde:

$\mathrm{Tg}$ - temperatura do termômetro de globo negro, ${ }^{\circ} \mathrm{C}$

To - temperatura do ponto de orvalho, ${ }^{\circ} \mathrm{C}$
O experimental foi montado em um delineamento inteiramente casualizado e analisado em um esquema fatorial $2 \times 2 \times 2$ e 10 repetições, sendo duas épocas do ano (época fria e época quente), dois tratamentos (com sombra - TCS e sem sombra - TSS) e dois períodos do dia (turno da manhã $-7 \mathrm{~h}$ e turno da tarde $-15 \mathrm{~h}$ ). Os resultados obtidos foram submetidos à análise de variância pelo programa Assistat (Silva \& Azevedo, 2009) e os valores médios foram comparados pelo teste de Tukey a $5 \%$ de probabilidade. Os valores de algumas variáveis meteorológicas e de ITGU foram submetidos à análise regressão.

\section{Resultados E Discussão}

As médias das variáveis climáticas estão apresentadas na Tabela 1. Observou-se efeito significativo $(\mathrm{p}<0,05)$ para todos os fatores apresentados.

Tabela 1. Médias das variáveis ambientais, temperatura do ar (Ta), umidade relativa do ar (UR), temperatura do globo negro (TGN), índice de temperatura do globo negro e umidade (ITGU) em função das épocas do ano (fria e quente), do ambiente (com sombreamento e sem sombreado) e dos turnos manhã $-7 \mathrm{~h}$ e tarde $-15 \mathrm{~h}$

\begin{tabular}{lccc}
\hline \multirow{2}{*}{ Fatores } & \multicolumn{3}{c}{ Variáveis meteorológicas } \\
\cline { 2 - 4 } Épocas do ano & Ta ( ${ }^{\circ} \mathrm{C}$ ) & UR (\%) & ITGU \\
Fria & $26,27 \mathrm{~B}$ & $61,01 \mathrm{~A}$ & $81,34 \mathrm{~B}$ \\
Quente & $31,91 \mathrm{~A}$ & $35,12 \mathrm{~B}$ & $87,43 \mathrm{~A}$ \\
\hline Tratamento & & & \\
Com sombra & $25,93 \mathrm{~B}$ & $59,22 \mathrm{~A}$ & $81,57 \mathrm{~B}$ \\
Sem sombra & $28,40 \mathrm{~A}$ & $52,98 \mathrm{~B}$ & $85,34 \mathrm{~A}$ \\
\hline Turno & & & \\
Manhã & $21,37 \mathrm{~B}$ & $80,37 \mathrm{~A}$ & $76,83 \mathrm{~B}$ \\
Tarde & 31,01 A & $40,60 \mathrm{~B}$ & $88,82 \mathrm{~A}$ \\
CV (\%) & \multicolumn{3}{c}{8,43} \\
\hline
\end{tabular}

* Médias seguidas por letras maiúsculas diferentes na coluna para cada fator são estatisticamente diferentes pelo teste de Tukey a $(0,05)$

Analisando o ITGU, nota-se um efeito significativo a 5\% de probabilidade entre os turnos da manhã e da tarde, entre os tratamentos e as épocas (Tabela 1). Segundo Santos (2003), ITGU até 79,0 indica um ambiente de conforto térmico para ovinos Santa Inês, ao passo que para Cezar et al. (2004) em condições de clima semiárido, ITGU de 82,4 define situação de perigo térmico para ovinos Santa Inês e seus mestiços. Verifica-se, portanto, que o valor de ITGU na época quente, independente do tratamento, sofreu efeito pronunciado das condições climáticas, o que pode ter proporcionado situação de desconforto.

Em trabalho realizado por Eustáquio Filho et al. (2011) no Sudoeste Baiano, onde ovinos da raça Santa Inês foram submetidas a ambiente com microclima controlado, foi ressaltado, como condição de conforto para os mesmos, um ambiente com temperatura de $25{ }^{\circ} \mathrm{C}$ e umidade de $65 \%$, valores esses próximos aos apresentados neste trabalho, em especial na época 1 (Tabela 1 ).

Para a FR verificou-se efeito significativo $(\mathrm{p}<0,05)$ para todos os fatores avaliados (Tabelas 2), ou seja, para épocas 
e tratamentos, quando considerados isoladamente. Houve interação entre os fatores época x tratamento, ou seja, a oferta de sombreamento interferiu na FR dos ovinos, fazendo com que esta procedesse de maneira distinta no TCS em especial no turno da tarde, quando comparado com o TSS.

Tabela 2. Frequência respiratória (movimentos respiratórios por minuto) de ovinos da raça Santa Inês sob pastejo em diferentes épocas do ano em função dos diferentes tratamentos

\begin{tabular}{|c|c|c|}
\hline & \multicolumn{2}{|c|}{ Tratamentos ${ }^{*}$} \\
\hline & Com sombra & Sem Sombra \\
\hline \multicolumn{3}{|c|}{ Épocas do ano } \\
\hline Fria & $30,24 \mathrm{bB}$ & $36,83 \mathrm{bA}$ \\
\hline Quente & $46,90 \mathrm{aB}$ & 54,98 aA \\
\hline CV (\%) & \multicolumn{2}{|c|}{8,55} \\
\hline
\end{tabular}

* Médias seguidas das mesmas letras minúsculas nas colunas e maiúsculas nas linhas não diferem entre si pelo Teste de Tukey a 0,05 de significância

Esta diferença observada na variável FR nos tratamentos também foi marcante nas diferentes épocas $(p<0,05)$ de maneira que tanto na época fria quanto na época quente, o tratamento sem sombra apresentou maior influência neste mecanismo termorregulatório cuja FR se mostrou no tratamento com sombreamento revelando menores médias principalmente na época fria com médias de 30,24 e $36,83 \mathrm{mov} \mathrm{mim}^{-1}$, para os tratamentos com e sem sombra, respectivamente (Tabela 2 ).

Ao se observar os maiores valores da FR nas duas épocas (36,83 e 54,98,93 $\mathrm{mov} \mathrm{min}^{-1}$ no turno da tarde das épocas fria e quente respectivamente) verifica-se que eles estão acima do intervalo tido como normal, de acordo com Reece (1996) e confirmado por Ribeiro et al. (2008) que é de 20 a 36 mov $\mathrm{mim}^{-1}$, indicando que os animais podem estar desconfortáveis visto que a FR é um bom indicador da situação de estresse térmico em ovinos, que usam o mecanismo como dissipador de calor, além de servir para quantificar a severidade do estresse calórico que, ao atingir 70 a $100 \mathrm{mov} \mathrm{mim}^{-1}$, é considerado animal estressado (Silanikove, 2000).

Santos (2004) citam, como normais para ovinos, FR entre 16 e $34 \mathrm{mov}^{\mathrm{min}^{-1}}$. Em relação à quantificação da severidade do estresse calórico os animais se mantiveram em uma faixa de estresse baixo durante a época fria no tratamento com sombra de acordo com Silanikove (2000), que afirma que FR de 40 a 60, 60 a 80 e de 80 a $120 \mathrm{mov} \mathrm{min}^{-1}$, caracteriza estresse baixo, médio-alto e alto para os pequenos ruminantes respectivamente e para ovinos em especial o estresse só seria considerado severo acima de 200.

O comportamento da FR difere daquele encontrado por Cezar et al. (2004) e Oliveira et al. (2005) que, ao avaliar parâmetros fisiológicos em ovinos Santa Inês, também encontraram médias bem superiores (80,39 movimento de ovino $\min ^{-1}$ ) e com base na classificação Silanikove (2000) pode-se dizer que os ovinos apresentaram estresse térmico alto no decorrer do dia. Comportamento semelhante foi verificado por Santos et al. (2005) e Souza et al. (2005).

No que diz respeito às diferentes formas de perda de calor para a manutenção da temperatura corpórea pode-se afirmar que, com a Ta fora da zona de conforto, a evaporação é apontada como a forma mais eficiente para perda de calor corpóreo caso em que se especificam os processos de respiração e sudação como alternativas para o animal. Combinando altas temperaturas e umidade do ar constantemente elevadas, o que se encontra é uma grande dificuldade para se processar a evaporação, formando-se gotículas de suor que escorrem pelo corpo dos animais acelerando um quadro de desidratação (Müller, 1982).

Neste sentido, a atividade respiratória é fundamental na tentativa de se evitar uma hipertermia e isto pode, de certa forma, explicar os elevados valores para FR durante essas avaliações uma vez que em muitos momentos tal combinação pôde ser observada em ambos os tratamentos, em especial na época quente, quando foram observados alguns dias com precipitação pluviométrica fora do normal para a mesma, propiciando que boa parte do dia permanecesse com umidade elevada, apesar do calor no piquete.

O comportamento observado até aqui nos remete a refletir sobre a importância de se lançar mão desta simples técnica de manejo que é o sombreamento, percebendo sua atuação como agente redutor de boa parte da radiação direta incidida sobre o animal, o que pode estar contribuindo para uma utilização menor dos mecanismos de perda de calor por meio da FR, que demanda maior gasto de energia pelo animal, que pode ser utilizada nos índices de produtividade, como descrito por Brasil et al. (2000).

Em geral, os ovinos apresentam uma TR média de aproximadamente $39,1{ }^{\circ} \mathrm{C}$ (Swenson, 1996), o que é demonstrado também por Piccione et al. (2007) e, de acordo com McDowell et al. (1976), cada $1{ }^{\circ} \mathrm{C}$ ou menos de elevação na temperatura retal pode ser o bastante para reduzir o desempenho na maioria das espécies de animais domésticos, inclusive em ovinos. Por essas e outras razões este parâmetro foi adotado como forma de medir a tolerância desses ovinos às condições climáticas do Vale do Submédio São Francisco, no semiárido nordestino.

Sendo assim foi possível verificar, através dos resultados, o comportamento referente às médias da TR (Tabela 3) cuja análise revelou efeito significativo $(\mathrm{p}<0,05)$ para o fator tratamento, não demonstrando efeito para as diferentes épocas.

Observa-se que o sombreamento influenciou, de forma significativa $(\mathrm{P}<0,05)$ a TR, de modo que, no tratamento com sombreamento $\left(38,29^{\circ} \mathrm{C}\right)$ ela foi inferior à do tratamento sem sombreamento $\left(38,44^{\circ} \mathrm{C}\right)$.

Apesar de não se observar interação entre os fatores avaliados para TR observam-se pequenas diferenças com os

Tabela 3. Temperatura retal de ovinos da raça Santa Inês sob pastejo em diferentes épocas do ano em função dos diferentes tratamentos

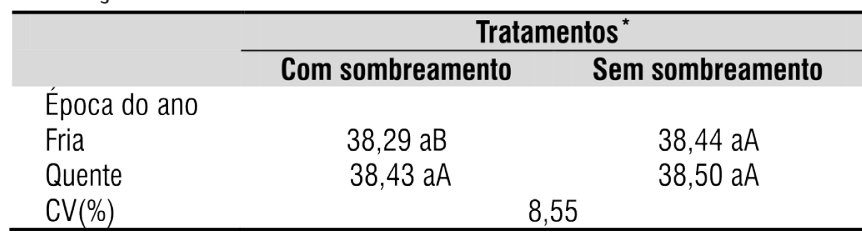

* Médias seguidas das mesmas letras minúsculas nas colunas e maiúsculas nas linhas não diferem entre si pelo Teste de Tukey a 0,05 de significância 
fatores isolados, com médias entre 38,29 e $38,50{ }^{\circ} \mathrm{C}$, e isto nos mostra que os animais apresentaram TR situadas dentro do intervalo tido como normal, que é de 38 a $40,5^{\circ} \mathrm{C}$ (Furtado, 2007).

De maneira geral constatou-se que o aumento considerado no ITGU à tarde, pode ter contribuído significativamente para o aumento da TR porém este aumento foi pronunciado de maneira proporcional nas duas épocas, o que fez com que este efeito não ficasse tão visível, não configurando um efeito de interação entre as épocas.

As médias referentes à temperatura da superfície cutânea (TC) em função da época e do tratamento estão representadas na Tabela 4. Constatou-se efeito significativo $(\mathrm{p}<0,05)$ para os valores de TC, em todos os fatores analisados.

Tabela 4. Médias para a temperatura da superfície cutânea (TC), de ovinos da raça Santa Inês sob pastejo em função da interação da época do ano com o tratamento

\begin{tabular}{|c|c|c|}
\hline & \multicolumn{2}{|c|}{ Tratamentos ${ }^{*}$} \\
\hline & Com sombreamento & Sem sombreamento \\
\hline \multicolumn{3}{|c|}{ Época do ano } \\
\hline Fria & $32,51 \mathrm{bB}$ & $34,52 \mathrm{bA}$ \\
\hline Quente & $36,66 \mathrm{aB}$ & 38,48 aA \\
\hline $\mathrm{CV}(\%)$ & \multicolumn{2}{|c|}{8,55} \\
\hline
\end{tabular}

* Médias seguidas das mesmas letras maiúsculas nas linhas e minúsculas nas colunas para os mesmos fatores, não diferem entre si pelo Teste de Tukey a 0,05 de significância

Com os valores verificados para tal variável nos dois tratamentos, nota-se que seu comportamento acompanha a tendência verificada para a TR e FR, confirmando a severidade de algumas variáveis ambientais na época mais quente.

Observando um ITGU médio de 82,85 durante o dia, percebe-se que os registros para médias de TC eram esperados, ainda mais ao se comparar esses valores obtidos com os resultados encontrados por Andrade et al. (2007) que, estudando parâmetros fisiológicos em ovinos Santa Inês submetidos a diferentes ambientes sombreados, encontraram valores médios de $\mathrm{TC}$ de 31,54 e $35,35{ }^{\circ} \mathrm{C}$ durante o dia, quando o ITGU variava entre de 73,28 e 83,61.

Em um estudo com caprinos Silva et al. (2005) obtiveram registros de maior TC no turno da tarde em relação ao turno da manhã (33,3 e $29,5{ }^{\circ} \mathrm{C}$, respectivamente) sob condições ambientais representadas por ITGU de 79,4 e 85,2, para os respectivos turnos, o que também foi verificado por Neiva et al. (2004). Resultados que corroboram com os encontrados nesta pesquisa em que a TC foi mais elevada durante a tarde, independente do ambiente disponibilizado aos animais.

De maneira geral, a TC acaba sendo diferenciada à medida que variações vão ocorrendo na TA e na UR, aumentando ou diminuindo a perda de calor para o meio, visando manter a homeotermia do animal. Andrade et al. (2007) encontraram semelhantes a este experimento, TC menores no tratamento com sombra $\left(31,39^{\circ} \mathrm{C}\right)$ do que no tratamento sem sombra e à tarde $\left(38,55^{\circ} \mathrm{C}\right)$.

Contudo, se ocorrer constantemente um aumento significativo da TC, a dissipação de calor fica comprometida através da forma sensível. Tornando-se necessária a dissipação de calor por meio da evaporação, seja ela através da pele ou por via respiratórias. Isto de certa maneira pôde ser verificado neste trabalho, a partir das médias de TC e FR dos animais do TSS, quando comparados com os do TCS.

\section{Conclusões}

O uso da tela de polipropileno com $80 \%$ de retenção luminosa proporcionou efeito positivo reduzindo, de maneira considerável, todas as variáveis fisiológicas na época mais quente do ano.

\section{Literatura Citada}

Andrade, I. S.; Souza, B. B.; Pereira Filho, J. M.; Silva, A. M. A. Parâmetros fisiológicos e desempeno de ovinos santa inês submetidos a diferentes tipos de sombreamento e a suplementação em pastejo. Ciência e Agrotecnologia, v.31, p.540-547, 2007.

Brasil, L. H. A.; Wechessler, F. S.; Bacari Júnior, F.; Gonçalves, H. C.; Bonassi, I. A. Efeito do estresse térmico sobre a produção, composição química do leite e respostas termorreguladoras de cabras da raça alpina. Revista Brasileira de Zootecnia, v.29, p.1639-1641, 2000.

Buffington, D. E. Black globe-humidity confort index for dairy cows. In: Winter meeting of the american society of agricultural engineers. St Joseph: ASAE, 1977. 4517p.

Cezar, M. F.; Souza, B. B.; Souza W. H.; Pimenta Filho, E. C.; Tavares, G. P.; Medeiros, G. X. Avaliação de parâmetros fisiológicos de ovinos Dorper, Santa Inês e seus mestiços perante condições climáticas do trópico semi-árido nordestino. Ciência e Agrotecnologia, v.28, p.614-620, 2004.

Encarnação, R.O. Estresse e produção animal. In: Ciclo Internacional de Palestras Sobre Bioclimatologia Animal, 1989. Jaboticabal. Anais... Jaboticabal: FUNEP. 1989, p.111-129.

Eustáquio Filho, A.; Teodoro, S. M.; Chaves, M. A.; Santos, P. E. F. dos; Silva, M. W. R. da; Murta, R. M.; Carvalho, G. P. de; Souza, L. E. B. de. Zona de conforto térmico de ovinos da raça Santa Inês com base nas respostas fisiológicas. Revista Brasileira de Zootecnia, v.40, p.1807-1814, 2011.

Furtado, G. D. Respostas termorreguladoras de cabras saanen submetidas a estresses térmico em lajes, Rio Grande do Norte. Natal: Departamento de Aprendizagem Rural, 2007. 11p.

IBGE - Instituto Brasileiro de Geografia e Estatística. Efetivo de bubalinos, caprinos e ovinos no Brasil-1970/2006. Rio de Janeiro: IBGE, 2006. v.35. 141p.

McDowell, R. E.; Hooven, N.W.; Camoens, J. K. Effects of climate on performance of Holsteins in first lactation. Journal Dairy Science, v.59, p.965-973, 1976.

Müller, P. B. Bioclimatologia aplicada aos animais domésticos. 2.ed. Porto Alegre: Sulina, 1982. 158p.

Neiva, J. N. M.; Teixeira, M.; Turco, S. H. N. Efeito do estresse climático sobre os parâmetros produtivos e fisiológicos de ovinos Santa Inês mantidos em confinamento na região litorânea do nordeste do Brasil. Revista Brasileira de Zootecnia, v.33, p.668-678, 2004. 
Oliveira, F. M. M.; Dantas, R. T.; Furtado, D. A.; Nascimento, J. W. B.; Medeiros, A. N. Parâmetros de conforto térmico e fisiológico de ovinos Santa Inês, sob diferentes sistemas de acondicionamento, Revista Brasileira de Engenharia Agrícola e Ambiental, v.9, p.631-635, 2005.

Piccione, G.; Borruso, M.; Fazio, F.; Giannetto, C.; Caola, G. Physiological parameters in lambs during the first 30 days postpartum. Small Ruminant Research, v.72, p.57-60, 2007.

Reece, W. O. Respiração nos mamíferos. In: Dukes, H. H.; Swenson, M. J. Fisiologia dos animais domésticos. 10.ed. Rio de Janeiro: Guanabara Koogan, 1996. p.199-205.

Ribeiro, N. L.; Furtado, D. A.; Medeiros, A. de N.; Ribeiro, M. N.; Silva, R. C. B.; Souza, C. M. S. Avaliação dos índices de conforto térmico, parâmetros fisiológicos e gradiente térmico de ovinos nativos. Revista Engenharia Agrícola, v.28, p.614-623, 2008.

Santos, F. C. B.; Sousa, B. B.; Alfaro, C. E. P.; César, M. F.; Pimenta Filho, E. C.; Acosta, A. A. A.; Santos, J. R. $\mathrm{S}$. Adaptabilidade de caprinos exóticos e naturalizados ao clima semi-árido do nordeste brasileiro. Ciência e Agrotecnologia, v.29, p.142-149. 2005.

Santos, J. R. S. Avaliação da adaptabilidade de ovinos Santa Inês Morada Nova e seus mestiços com a raça Dorper, ao semi-árido. Patos: UFCG, 2004. 31p.

Santos, J. R. S.; Souza, B. B.; Souza, W. H.; Cezar, M. F.; Tavares, G. P. Avaliação da adaptabilidade de ovinos da raça Santa Inês, morada nova e mestiços de dorper, no semi-árido. In: Reunião Anual da Sociedade Brasileira de Zootecnia, 40, 2003, Santa Maria. Anais... Santa Maria: SBZ, 2003. p.1-5.
Santos, R. A cabra e a ovelha no Brasil. Uberaba: Agropecuária Tropical, 2003. 479p.

Silanikove, N. Effects of heat stress on the welfare of extensively managed 1059 domestic ruminants. Livestock Production Science, v.67, p.1-18, 2000.

Silva, F. de A. S.; Azevedo, C. A. V. de. principal components analysis in the software ssistat-statistical attendance. In: World Congress on Computers in Griculture, 7, 2009, Reno. Anais...Reno: American Society of Agricultural and Biological Engineers, 2009. CD Rom

Silva, R. R.; Silva, F. F.; Carvalho, G. G. P.; Veloso, C. M.; Franco, I. L.; Aguiar, M. S. M. A.; Chaves, M. A.; Cardoso, C. P. Avaliação do comportamento ingestivo de novilhas 3/4 holandês x zebu alimentadas com silagem de capimelefante acrescida de $10 \%$ de farelo de mandioca. Ciência Animal Brasileira, v.6, p.134-141, 2005.

Souza, D. E.; Souza, B. B.; Souza, W. H.; Cezar, M. F.; Santos, J. R. S.; Tavares, G. P. Determinação dos parâmetros fisiológicos e gradiente térmico de diferentes grupos genéticos de caprinos no semi-árido. Ciência e Agrotecnologia, v.29, p.177-184. 2005.

Swenson, M. J.; Reece, W. O. D Fisiologia dos animais domésticos. II.ed. Rio de Janeiro: Guanabara Koogan, 1996. 855p.

Teixeira. A. H. C.; Lima Filho. J. M. P. Cultivo da mangueira: Potencial climático da região do Submédio São Francisco. Sistema de produção 2, Versão eletrônica, Julho de 2004. 